\title{
Protective Clothing
}

National Cancer Institute

\section{Source}

National Cancer Institute. Protective Clothing. NCI Thesaurus. Code C95904.

Clothing designed to protect the wearer from injury or exposure to hazardous conditions or substances. 